\title{
Expression of HMB45, MelanA and SOX10 is rare in non-small cell lung cancer
}

\author{
Mark Kriegsmann ${ }^{1 *}$, Katharina Kriegsmann², Alexander Harms ${ }^{1,3}$, Rémi Longuespée ${ }^{1}$, Christiane Zgorzelski ${ }^{1}$, \\ Jonas Leichsenring ${ }^{1}$, Thomas Muley ${ }^{3,4}$, Hauke Winter ${ }^{3,5}$, Daniel Kazdal ${ }^{1,3}$, Benjamin Goeppert ${ }^{1}$ and Arne Warth ${ }^{1,6}$
}

\begin{abstract}
Background: Non-small cell lung cancer (NSCLC) and melanoma are frequent entities in routine diagnostics. Whereas the differential diagnosis is usually straight forward based on histomorphology, it can be challenging in poorly differentiated tumors as melanoma may mimic various histological patterns. Distinction of the two entities is of outmost importance as both are treated differently. HMB45 and MelanA are recommended immunohistological markers for melanoma in this scenario. SOX10 has been described as an additional marker for melanoma. However, comprehensive large-scale data about the expression of melanoma markers in NSCLC tumor tissue specimen are lacking so far.
\end{abstract}

Methods: Therefore, we analyzed the expression of these markers in 1085 NSCLC tumor tissue samples. Tissue microarrays of NSCLC cases were immunohistochemically stained for HMB45, MelanA, and SOX10. Positivity of a marker was defined as $\geq 1 \%$ positive tumor cells.

Results: In 1027 NSCLC tumor tissue samples all melanoma as well as conventional immunohistochemical markers for NSCLC could be evaluated. HMB45, MelanA, and SOX10 were positive in $1(<1 \%), 0(0 \%)$ and $5(<1 \%)$ cases. The HMB45 positive case showed co-expression of SOX10 and was classified as large cell carcinoma. Three out of five SOX10 positive cases were SqCC and one case was an adenosquamous carcinoma.

Conclusions: Expression of HMB45, MelanA and SOX10 is evident but exceedingly rare in NSCLC cases. Together with conventional immunomarkers a respective marker panel allows a clear-cut differential diagnosis even in poorly differentiated tumors.

Keywords: NSCLC, Lung cancer, SOX10, HMB45, MelanA, Immunohistochemistry

\section{Background}

Non-small cell lung cancer (NSCLC) and melanoma are frequent entities in pathological routine diagnostics. Whereas the differential diagnosis is often feasible based on histomorphology alone, especially in resection specimens or when melanin pigment is evident, the distinction of both can be challenging in small biopsies or cytology preparations. This is especially true for cases with undifferentiated morphology as melanoma may mimic various histological patterns [1]. Although, a tumor situated in the lung is more likely to be lung cancer, the lung is a frequent site of metastatic spread especially in

\footnotetext{
* Correspondence: mark.kriegsmann@med.uni-heidelberg.de

${ }^{1}$ Institute of Pathology, University Hospital Heidelberg, Im Neuenheimer Feld 224, Heidelberg, Germany

Full list of author information is available at the end of the article
}

patients with NRAS-mutated melanoma [2,3] and primary melanoma of the lung is recognized in the literature as well [4-6]. Distinction of the two entities is of outmost importance as both are treated differently $[7,8]$. Of note, the common BRAF mutations in melanoma (usually V600E) [9] can be found in pulmonary adenocarcinomas (usually non-V600E) [9-11]. Commonly applied immunohistological markers in this scenario are S100, Human Melanoma Black (HMB45), melanoma antigen recognized by $\mathrm{T}$ cells 1 (MelanA), SRY-related HMG-box 10 (SOX10), cytokeratin 5/6 (CK5/6), NapsinA, p63 (p40) and thyroid transcription factor-1 (TTF-1) $[12,13]$. While the expression of CK5/6, NapsinA, p63 and TTF-1 has been extensively studied in NSCLC $[14,15]$ and the immunoreactivity of S100, HMB45, MelanA and SOX10 is well described for melanoma [16], the 
comprehensive expression of melanoma markers in NSCLC has not been analyzed in a large NSCLC tumor tissue cohort to date, except for S100 [17]. This is surprising as especially SOX10 has prompted recent interest and has been reported in various other cancer entities. Therefore, we systematically analyzed the expression of HMB45, MelanA, SOX10, CK5/6, NapsinA, p63 and TTF-1 in 1027 NSCLC cases including 498 adenocarcinomas (ADC), 424 squamous cell carcinomas (SqCC), 44 adenosquamous carcinomas (ADSqCC), 51 large cell carcinomas (LC) and 10 pleomorphic carcinomas (PC).

\section{Methods}

\section{Cohort characteristics}

Formalin-fixed and paraffin embedded NSCLC tumor tissue specimens resected from 2004 to 2007 in the Thoracic Hospital Heidelberg were extracted from the archive of the Institute of Pathology, Heidelberg University, with the support of the tissue bank of the National Center for Tumor Diseases (\#2508, ethics committee University of Heidelberg \#S-205). Tissues were used in accordance with the ethical regulations of the NCT tissue bank defined by the local ethics committee and according to the Declaration of Helsinki. Diagnoses were made according to the recommendations of the World Health Organization classification for lung cancer 2015 [12]. A cohort of 1085 NSCLC cases was selected. Tissue microarray construction was done as described previously $[15,18,19]$. The results from the conventional NSCLC markers CK5/6, NapsinA, p63 and TTF-1 were stained and published previously [15]. A detailed description of the clinical characteristics of the NSCLC tumor tissue cohort is provided in Table 1.

\section{Immunohistochemistry}

Immunohistochemical staining was performed as previously described [20]. In brief, slides were deparaffinized, pre-treated with an antigen retrieval buffer and stained using an automated device. Conventional NSCLC markers were stained on a Techmate 500plus (Dako, Hamburg, Germany) and melanoma-markers on a Ventana Benchmark Ultra (Roche, Rotkreuz, Switzerland). The antibody and staining characteristics are shown in Table 2. Staining was evaluated based on positivity of $>1 \%$ positive tumor cells by an experienced pathologist (M.K.). The cut-off of $1 \%$ positive tumor cells was chosen to avoid classification of minimal staining (which would likely be background staining) as positive. Typical examples of positive and negative samples of the respective antibodies are shown in Fig. 1.

\section{Data analysis and software}

All statistical analyses were done in R-Statistical Software (www.r-project.org, v.3.4.2, Free Software Foundation) and R-Studio (v.1.1.383, Affero General Public License,
Table 1 Clinical characteristics of the cohort

\begin{tabular}{|c|c|}
\hline Patients, $n$ & 1027 \\
\hline Median age, years (range) & $64(30-85)$ \\
\hline Patient gender & n (\%) \\
\hline Male & $734(71)$ \\
\hline Female & $293(29)$ \\
\hline \multicolumn{2}{|l|}{ Histology } \\
\hline ADC & $498(48)$ \\
\hline SqCC & $424(41)$ \\
\hline ADSqCC & $44(4)$ \\
\hline LC & $51(5)$ \\
\hline PC & $10(1)$ \\
\hline \multicolumn{2}{|l|}{ TNM-Classification } \\
\hline pT1a & $84(8)$ \\
\hline pT1b & $114(11)$ \\
\hline pT2a & $484(47)$ \\
\hline pT2b & $170(17)$ \\
\hline pT3 & $155(15)$ \\
\hline pT4 & $20(2)$ \\
\hline pNO & $503(49)$ \\
\hline $\mathrm{pN1}$ & $244(24)$ \\
\hline pN2 & $249(24)$ \\
\hline pN3 & $6(1)$ \\
\hline pNX & $25(2)$ \\
\hline pM1 & $25(2)$ \\
\hline pM0 & $1002(98)$ \\
\hline \multicolumn{2}{|l|}{ Clinical stage } \\
\hline IA & $133(13)$ \\
\hline $\mathrm{IB}$ & $255(25)$ \\
\hline$\| \mathrm{A}$ & $209(20)$ \\
\hline$\| \mathrm{B}$ & $105(10)$ \\
\hline$\| \mathrm{A}$ & $286(28)$ \\
\hline$\| I B$ & $14(1)$ \\
\hline IV & $25(2)$ \\
\hline
\end{tabular}

$A D C$, adenocarcinoma, $A D S q C C$, adenosquamous carcinoma, $L C$, large cell carcinoma, n, number, SqCC, squamous cell carcinoma

Boston, USA). The Figure was created in Inkscape (v. 0.92) and Powerpoint (Microsoft, Redmond, USA).

\section{Results}

Evaluation of tissue microarrays

In a total of 1027 NSCLC tumor tissue specimen HMB45, MelanA, SOX10, CK5/6, NapsinA, p63, and TTF-1 could be evaluated. In the other cases one or more of the conventional stainings (CK5/6, NapsinA, p63 and TTF-1) could not be analyzed due to floating or rolling of tissue cores. The drop-out rate was $5 \%$. All neglected cases were negative for HMB45, MelanA and SOX10. 
Table 2 Antibodies used in this study and staining conditions

\begin{tabular}{|c|c|c|c|c|c|c|}
\hline Antibody & Company & Clone & Pretreatment & $\begin{array}{l}\text { Buffer incubation } \\
\text { time (min) }\end{array}$ & $\begin{array}{l}\text { Antibody incubation } \\
\text { time (min) }\end{array}$ & Dilution \\
\hline CK5/6 & Dako & D5/16 B4 & Tris/Borat/EDTA, pH 9 & 56 & 24 & $1: 50$ \\
\hline HMB45 & Dako & HMB45 & Tris/Borat/EDTA, pH 8.4 & 64 & 24 & $1: 75$ \\
\hline MelanA & Ventana & A103 & Tris/Borat/EDTA, pH 8.4 & 64 & 24 & RTU \\
\hline SOX10 & Cell Marque & EP268 & Tris/Borat/EDTA, pH 8.4 & 48 & 24 & 1:100 \\
\hline Napsin A & Novocastra & IP64 & Tris/Borat/EDTA, pH 6 & 32 & 24 & 1:400 \\
\hline p63 & DCS Immunoline & $4 \mathrm{~A} 4$ & Tris/Borat/EDTA, pH 6 & 40 & 24 & $1: 25$ \\
\hline TTF-1 & Novocastra & SPT24 & Tris/Borat/EDTA, pH 9 & 56 & 24 & $1: 200$ \\
\hline
\end{tabular}

CK, cytokeratin, HMB45, Human Melanoma Black 45, SOX10, SRY-related HMG-box 10 protein, TTF-1, thyroid transcription factor-1

Expression of conventional NSCLC markers CK5/6, NapsinA, p63, and TTF-1

CK5/6, NapsinA, p63 and TTF-1 were positive in 457 (44\%), 409 (40\%), 510 (50\%) and 502 (49\%) cases, respectively. While CK5/6 and p63 were most commonly expressed in SqCC (403 (95\%) and 405 (95\%)), NapsinA and TTF-1 were mainly positive in ADC (371 (74\%) and $436(88 \%))$.

Expression of melanoma markers HMB45, MelanA, and SOX10 and interplay with conventional NSCLC markers HMB45, MelanA, and SOX10 were positive in $1(<1 \%), 0$ $(0 \%)$ and $5(<1 \%)$ of cases respectively. The HMB45 positive case showed co-expression of SOX10. This particular case was also positive for AE1/3, CK7, CK5/6 (focal). NapsinA, TTF-1, p40, p63, CD56, synaptophysin, S100 as well as MelanA were negative. Based on morphology and immunohistochemistry this sample was classified as LC. All of the five SOX10 positive cases were also positive for CK5/6, three were positive for p63 and all were negative for NapsinA and TTF-1. Three out of five SOX10 positive cases were classified as SqCC, one was classified as ADSqCC based on the resection specimen. The other histological subtypes (ADC or PC) showed no expression of melanoma markers.
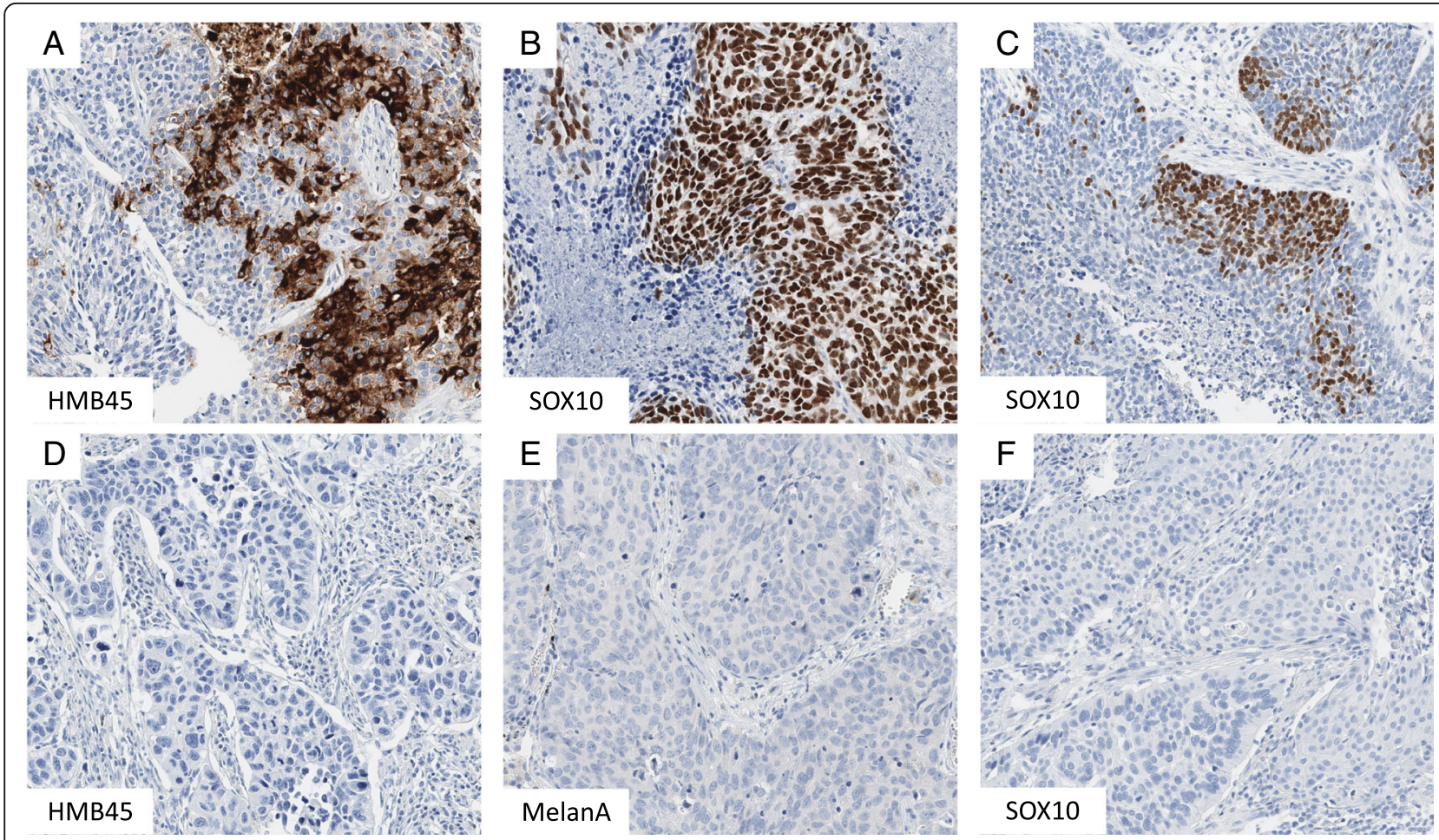

Fig. 1 Examples of immunohistochemical stainings. Positive (a-c) and negative (d-f) examples of HMB45 (a, d) and SOX10 (b, c, f) are displayed. A representative image of a negative MelanA stain (e) in SqCC is also demonstrated. SOX10 expression reached from strong expression in all tumor cells (b) to focal positivity in only a subset of cells (c). Mag.: 200x. HMB45, Human Melanoma Black 45, SqCC, squamous cell carcinoma, SOX10, SRY-related HMG-box 10 protein 


\section{Discussion}

As novel targeted therapies for melanoma and NSCLC are available which show impressive effects, the differentiation of both entities is essential. However, little is known about the expression of melanoma markers in NSCLC tissue specimens, except for S100 [17]. In the present study we analyzed HMB45, MelanA, SOX10, CK5/6, NapsinA, p63, and TTF-1 in a large cohort of NSCLC cases and demonstrate that expression of melanoma markers is rare. A small subset of SqCC, LC and ADSqCC may be positive for SOX10.

HMB45 is a monoclonal antibody that has been first described in 1986 [21] and recognizes melanosomal glycoprotein gp100 (Pmel17). The anti-MelanA murine monoclonal antibody A103 [22] has been described in the late 1990s. Both are commonly applied in thoracic pathology for the detection of melanocytic tumors [2, 13], and to exclude rare thoracic tumors such as perivascular epitheloid cell tumors (PEComa) including lymphangioleiomyomatosis [23] or clear cell sugar tumor [24] as well as for the diagnosis of clear cell sarcoma of soft parts [25]. Besides its role in the differential diagnosis of thoracic tumors, HMB45 and MelanA expression has been demonstrated in sex-chord stromal tumors [26], $\mathrm{t}(6 ; 11)(\mathrm{p} 21 ; \mathrm{q} 12)$-translocation associated renal cell neoplasms [27], endometrial stromal sarcomas [28] and nerve sheet tumors [29].

A more recently described melanocytic immunomarker is SOX10 which regulates Wnt/ $\beta$-catenin signaling, contributes to stem/progenitor activity and induces a mesenchymal transition expression [30,31]. It has been suggested to be a useful marker for the differential diagnosis of melanocytic lesions [32,33]. However, expression of SOX10 has also been recently described in benign adnexal skin tumors such as cylindroma and spiradenoma (uniformly positive) [34], schwannoma [33], in tumors of myoepithelial origin [33] and in a subset of malignant neoplasms for instance bladder cancer [35], breast cancer [36], ependymoma [37], gastric adenocarcinoma [38], hepatocellular carcinoma [39], nasopharyngeal carcinoma [40], ovarian tumors [41], prostate cancer [42], salivary gland tumors [43, 44], and squamous cell carcinoma of head and neck [33]. SOX10 positivity is usually restricted to a small subset of carcinomas $(<10 \%)$ except for triple-negative breast cancer that may more frequently express SOX10 [33].

To the best of our knowledge, HMB45, MelanA and SOX10 expression has not been evaluated in a large NSCLC cohort > 1000 samples so far and has been investigated only in a limited number of patients [45]. The later study included five normal lung samples and 25 neoplastic lung cancer samples, all of which were negative for SOX10. Miettinen et al. reported occasional SOX10 expression in SqCC of lungs and in one well-differentiated fetal pulmonary ADC, but they did not specify the number of positive $\mathrm{SqCC}$ cases, nor the overall number of lung cancer samples analyzed. In line with the expression of SOX10 in myoepithelial and basal cells, a subset of pulmonary SqCC have been described to be positive for the basal type cytokeratin CK15 [46]. However, the biological role of the expression of basal cell markers in NSCLC tissue specimen remains to be investigated. In our study we found only one HMB45 positive case classified as LC, which had co-expression of SOX10. SOX10 positivity was observed in five out of 1085 cases. Three of them were SqCC and one case was ADSqCC. None of the ADC or PC showed expression of melanocytic markers.

\section{Conclusions}

In summary, we demonstrate in a large NSCLC tumor tissue cohort that expression of HMB45, MelanA, and SOX10 is exceedingly rare in NSCLC cases and almost restricted to tumors with squamous differentiation. Thus, together with the conventional immunomarkers for NSCLC, a marker panel including these stainings is valuable in the differential diagnosis of thoracic neoplasms and melanoma and will lead to a definite diagnosis even in poorly differentiated tumors.

\section{Abbreviations}

ADC: adenocarcinoma; ADSqCC: adenosquamous carcinoma; BRAF: v-Raf murine sarcoma viral oncogene homolog B; CK: cytokeratin; HMB45: Human Melanoma Black 45; LC: large cell carcinoma; MelanA: melanoma antigen recognized by T cells 1; NRAS: Neuroblastoma RAS viral oncogene homolog; NSCLC: non-small cell lung cancer; PC: pleomorphic carcinoma;

PEComa: perivascular epitheloid cell tumor; SOX10: SRY-related HMG-box 10; SqCC: squamous cell carcinoma; TTF1: thyroid transcription factor-1

\section{Acknowledgements}

We acknowledge financial support by Deutsche Forschungsgemeinschaft within the funding programme Open Access Publishing, by the BadenWürttemberg Ministry of Science, Research and the Arts and by RuprechtKarls-Universität Heidelberg.

\section{Availability of data and materials}

Is available upon request from the corresponding author.

\section{Authors' contributions}

MK designed the study, performed the evaluation of the IHC stains, participated in data analysis and drafted the manuscript. $A H, R L, K K, J L, D K$ and BG participated in data analysis. TM and HW provided tissue specimens. AW financed the study and participated in evaluation of the IHC stains. All authors reviewed the manuscript for important intellectual content. All authors read and approved the final manuscript.

\section{Ethics approval and consent to participate}

Ethics approval and consent to participate was given by all patients in writing (ethics approval was given by the ethics committee, University of Heidelberg).

\section{Consent for publication}

Written informed consent for publication of their clinical details was obtained from the patients.

Competing interests

The authors declare that they have no competing interests. 


\section{Publisher's Note}

Springer Nature remains neutral with regard to jurisdictional claims in published maps and institutional affiliations.

\section{Author details \\ 'Institute of Pathology, University Hospital Heidelberg, Im Neuenheimer Feld 224, Heidelberg, Germany. ${ }^{2}$ Department of Internal Medicine V, Hematology, Oncology and Rheumatology, University Hospital Heidelberg, Heidelberg, Germany. ${ }^{3}$ Translational Lung Research Centre Heidelberg, Member of the German Centre for Lung Research, Heidelberg, Germany. ${ }^{4}$ Translational Research Unit, Thoraxklinik at Heidelberg University, Heidelberg, Germany. ${ }^{5}$ Department of Thoracic Surgery, Thoraxklinik at Heidelberg University, Heidelberg, Germany. ${ }^{6}$ Present address: Institute of Pathology, Cytopathology, and Molecular Pathology, UEGP, Gießen, Wetzlar, Limburg, Germany.}

\section{Received: 28 June 2018 Accepted: 3 September 2018}

\section{Published online: 11 September 2018}

\section{References}

1. Plaza JA, Torres-Cabala C, Evans H, Diwan HA, Suster S, Prieto VG. Cutaneous metastases of malignant melanoma: a clinicopathologic study of 192 cases with emphasis on the morphologic spectrum. Am J Dermatopathol. 2010; 32(2):129-36.

2. Wick MR, Gru AA. Metastatic melanoma: pathologic characterization, current treatment, and complications of therapy. Semin Diagn Pathol. 2016;33(4):204-18.

3. Adler NR, Wolfe R, Kelly JW, Haydon A, McArthur GA, McLean CA, et al. Tumour mutation status and sites of metastasis in patients with cutaneous melanoma. Br J Cancer. 2017;117(7):1026-35.

4. Peng J, Han F, Yang T, Sun J, Guan W, Guo X. Primary malignant melanoma of the lung: a case report and literature review. Medicine. 2017:96(46):e8772.

5. Yamamoto Y, Kodama K, Maniwa T, Takeda M, Tanaka Y, Ozawa K, et al. Primary malignant melanoma of the lung: a case report. Mol Clin Oncol. 2017;7(1):39-41.

6. Wilson RW, Moran CA. Primary melanoma of the lung: a clinicopathologic and immunohistochemical study of eight cases. Am J Surg Pathol. 1997; 21(10):1196-202.

7. Dimitriou F, Braun RP, Mangana J. Update on adjuvant melanoma therapy Curr Opin Oncol. 2018:30(2):118-24.

8. Waxman ES, Fossella FV. Biomarkers/molecular targets, immunotherapy, and treatments for non-small cell lung Cancer. J Adv Pract Oncol. 2016;7(5):514-24.

9. Pfarr N, Penzel R, Klauschen F, Heim D, Brandt R, Kazdal D, et al. Copy number changes of clinically actionable genes in melanoma, non-small cell lung cancer and colorectal cancer-a survey across 822 routine diagnostic cases. Genes Chromosomes Cancer. 2016;55(11):821-33.

10. Warth A, Endris V, Stenzinger A, Penzel R, Harms A, Duell T, et al. Genetic changes of non-small cell lung cancer under neoadjuvant therapy. Oncotarget. 2016;7(20):29761-9.

11. Warth A, Penzel R, Lindenmaier $H$, Brandt R, Stenzinger A, Herpel E, et al. EGFR, KRAS, BRAF and ALK gene alterations in lung adenocarcinomas: patient outcome, interplay with morphology and immunophenotype. Eur Respir J. 2014:43(3):872-83

12. BE TWD, Burke AP, Marx A, Nicholson AG. In: BE TWD, Burke AP, Marx A, Nicholson AG, editors. WHO Classification of Tumours of the Lung, Pleura, Thymus and Heart. 4th ed: IARC Publication. 2015;7:1-412.

13. Brenn T. Histological spectrum of malignant melanoma. Pathologe. 2015; 36(1):53-61.

14. Warth A. Diagnosis, prognosis, and prediction of non-small cell lung cancer. Importance of morphology, immunohistochemistry and molecular pathology. Der Pathologe. 2015;36(Suppl 2):194-200.

15. Warth A, Muley T, Herpel E, Meister M, Herth FJ, Schirmacher P, et al. Largescale comparative analyses of immunomarkers for diagnostic subtyping of non-small-cell lung cancer biopsies. Histopathology. 2012;61(6):1017-25.

16. Parra-Medina R, Morales SD. Diagnostic utility of epithelial and melanocitic markers with double sequential immunohistochemical staining in differentiating melanoma in situ from invasive melanoma. Ann Diagn Pathol. 2017:26:70-4.

17. Jassem E, Serkies K, Dziadziuszko R, Drozdowska A, Kobierska-Gulida G, Skokowski J, et al. Prognostic value of S-100 immunostaining in tumour cells of non-small cell lung cancer. Biomarkers. 2006;11(3):262-9.
18. Lisenko K, Leichsenring J, Zgorzelski C, Longuespee R, Casadonte R, Harms A, et al. Qualitative comparison between carrier-based and classical tissue microarrays. In: Applied immunohistochemistry \& molecular morphology: AlMM/official publication of the Society for Applied Immunohistochemistry; 2017.

19. Kriegsmann M, Harms A, Longuespee R, Muley T, Winter H, Kriegsmann K, et al. Role of conventional Immunomarkers, HNF4-a, and SATB2 in the differential diagnosis of pulmonary and colorectal adenocarcinomas. Histopathology. 2018;72(6):997-1006.

20. Kriegsmann M, Muley T, Harms A, Tavernar L, Goldmann T, Dienemann H, et al. Differential diagnostic value of CD5 and CD117 expression in thoracic tumors: a large scale study of 1465 non-small cell lung cancer cases. Diagn Pathol. 2015;10:210.

21. Gown AM, Vogel AM, Hoak D, Gough F, McNutt MA. Monoclonal antibodies specific for melanocytic tumors distinguish subpopulations of melanocytes. Am J Pathol. 1986;123(2):195-203.

22. Jungbluth AA, Busam KJ, Gerald WL, Stockert E, Coplan KA, Iversen K, et al. A103: an anti-melan-a monoclonal antibody for the detection of malignant melanoma in paraffin-embedded tissues. Am J Surg Pathol. 1998:22(5):595-602.

23. Grzegorek I, Lenze D, Chabowski M, Janczak D, Szolkowska M, Langfort R, et al. Immunohistochemical evaluation of pulmonary lymphangioleiomyomatosis. Anticancer Res. 2015;35(6):3353-60

24. Tsilimigras DI, Bakopoulos A, Ntanasis-Stathopoulos I, Gavriatopoulou M, Moris D, Karaolanis G, et al. Clear cell "sugar tumor" of the lung: diagnostic features of a rare pulmonary tumor. Respir Med Case Rep. 2018;23:52-4.

25. Goh GH, Teh M, Vanecek T, Moran C, Petersson F. Primary pulmonary clear cell sarcoma-the first two reported cases. Virchows Archiv. 2016;469(1):111-7.

26. Deavers MT, Malpica A, Ordonez NG, Silva EG. Ovarian steroid cell tumors: an immunohistochemical study including a comparison of calretinin with inhibin. Int J Gynecol Pathol. 2003;22(2):162-7.

27. Petersson F, Vanecek T, Michal M, Martignoni G, Brunelli M, Halbhuber Z, et al. A distinctive translocation carcinoma of the kidney; "rosette forming," $t(6$; 11), HMB45-positive renal tumor: a histomorphologic, immunohistochemical, ultrastructural, and molecular genetic study of 4 cases. Hum Pathol. 2012;43(5):726-36.

28. Albores-Saavedra J, Dorantes-Heredia R, Chable-Montero F, Chanona-Vilchis J, Perez-Montiel D, Lino-Silva LS, et al. Endometrial stromal sarcomas: immunoprofile with emphasis on HMB45 reactivity. Am J Clin Pathol. 2014; 141(6):850-5.

29. Motoi T, Ishida T, Kawato A, Motoi N, Fukayama M. Pigmented neurofibroma: review of Japanese patients with an analysis of melanogenesis demonstrating coexpression of c-met protooncogene and microphthalmia-associated transcription factor. Hum Pathol. 2005;36(8):871-7.

30. Tudrej KB, Czepielewska E, Kozlowska-Wojciechowska M. SOX10-MITF pathway activity in melanoma cells. Arch Med Sci. 2017;13(6):1493-503.

31. Gambichler T, Petig AL, Stockfleth E, Stucker M. Expression of SOX10, ABCB5 and CD271 in melanocytic lesions and correlation with survival data of patients with melanoma. Clin Exp Dermatol. 2016;41(7):709-16.

32. Plaza JA, Bonneau P, Prieto V, Sangueza M, Mackinnon A, Suster D, et al. Desmoplastic melanoma: an updated immunohistochemical analysis of 40 cases with a proposal for an additional panel of stains for diagnosis. J Cutan Pathol. 2016;43(4):313-23.

33. Miettinen M, McCue PA, Sarlomo-Rikala M, Biernat W, Czapiewski P, Kopczynski J, et al. Sox10--a marker for not only schwannian and melanocytic neoplasms but also myoepithelial cell tumors of soft tissue: a systematic analysis of 5134 tumors. Am J Surg Pathol. 2015;39(6):826-35.

34. Lezcano C, Ho J, Seethala RR. Sox10 and DOG1 expression in primary adnexal tumors of the skin. Am J Dermatopathol. 2017;39(12):896-902

35. Yin H, Qin C, Zhao Y, Du Y, Sheng Z, Wang Q, et al. SOX10 is over-expressed in bladder cancer and contributes to the malignant bladder cancer cell behaviors. Clin transl oncol. 2017;19(8):1035-44.

36. Nelson ER, Sharma R, Argani P, Cimino-Mathews A. Utility of Sox10 labeling in metastatic breast carcinomas. Hum Pathol. 2017;67:205-10.

37. Mezencev R, Svajdler M. On Ependymomas and SOX10. J Neuropathol Exp Neurol. 2017;76(2):155-7.

38. Kato M, Nishihara $\mathrm{H}$, Hayashi $\mathrm{H}$, Kimura $\mathrm{T}$, Ishida $\mathrm{Y}$, Wang L, et al. Clinicopathological evaluation of Sox10 expression in diffuse-type gastric adenocarcinoma. Med Oncol. 2017:34(1):8.

39. Zhou D, Bai F, Zhang X, Hu M, Zhao G, Zhao Z, et al. SOX10 is a novel oncogene in hepatocellular carcinoma through Wnt/beta-catenin/TCF4 cascade. Tumour biology. 2014;35(10):9935-40. 
40. Zhao Y, Liu ZG, Tang J, Zou RF, Chen XY, Jiang GM, et al. High expression of Sox 10 correlates with tumor aggressiveness and poor prognosis in human nasopharyngeal carcinoma. OncoTargets and therapy. 2016;9:1671-7.

41. Kwon AY, Heo I, Lee HJ, Kim G, Kang H, Heo JH, et al. Sox10 expression in ovarian epithelial tumors is associated with poor overall survival. Virchows Archiv. 2016;468(5):597-605.

42. Zhong WD, Qin GQ, Dai QS, Han ZD, Chen SM, Ling XH, et al. SOXs in human prostate cancer: implication as progression and prognosis factors. BMC Cancer. 2012;12:248.

43. Ivanov SV, Panaccione A, Nonaka D, Prasad ML, Boyd KL, Brown B, et al. Diagnostic SOX10 gene signatures in salivary adenoid cystic and breast basal-like carcinomas. Br J Cancer. 2013;109(2):444-51.

44. Hsieh MS, Lee YH, Chang YL. SOX10-positive salivary gland tumors: a growing list, including mammary analogue secretory carcinoma of the salivary gland, sialoblastoma, low-grade salivary duct carcinoma, basal cell adenoma/adenocarcinoma, and a subgroup of mucoepidermoid carcinoma. Hum Pathol. 2016:56:134-42.

45. Mohamed A, Gonzalez RS, Lawson D, Wang J, Cohen C. SOX10 expression in malignant melanoma, carcinoma, and normal tissues. Appl immunohistochem mol morphol. 2013;21(6):506-10.

46. Kriegsmann M, Casadonte R, Kriegsmann J, Dienemann $H$, Schirmacher $P$, Hendrik Kobarg J, et al. Reliable entity subtyping in non-small cell lung Cancer by matrix-assisted laser desorption/ionization imaging mass spectrometry on formalin-fixed paraffin-embedded tissue specimens. Mol cell proteomics. 2016;15(10):3081-9.

Ready to submit your research? Choose BMC and benefit from:

- fast, convenient online submission

- thorough peer review by experienced researchers in your field

- rapid publication on acceptance

- support for research data, including large and complex data types

- gold Open Access which fosters wider collaboration and increased citations

- maximum visibility for your research: over $100 \mathrm{M}$ website views per year

At $\mathrm{BMC}$, research is always in progress.

Learn more biomedcentral.com/submissions 